In the article "Potential Inhibitors of Chemokine Function: Analysis of Noncovalent Complexes of CC Chemokine and Small Polyanionic Molecules by ESI FT-ICR Mass Spectrometry" which appeared in Volume 17, Number 4, April 2006, Pages 524-535 two authors are to be added to the list. The first page of the article should look like so:

\title{
Potential Inhibitors of Chemokine Function: Analysis of Noncovalent Complexes of CC Chemokine and Small Polyanionic Molecules by ESI FT-ICR Mass Spectrometry
}

\author{
Yonghao Yu, ${ }^{*}$ Matthew D. Sweeney, ${ }^{\dagger}$ Ola M. Saad ${ }^{\ddagger}$ \\ Genome Center, Departments of Chemistry and Molecular Cell Biology, University of California, Davis, \\ California, USA
}

\section{Susan E. Crown}

Department of Molecular and Cell Biology, Department of Chemistry, University of California, Berkeley, CA, USA

\section{Tracy M. Handel}

Skaggs School of Pharmacy and Pharmaceutical Sciences, University of California, San Diego, CA, USA

\section{Julie A. Leary}

Genome Center, Departments of Chemistry and Molecular Cell Biology, University of California, Davis, California, USA

Also, there are added entries to the Acknowledgments section.

TMH gratefully acknowledges support form the National Institutes of Health (NIH RO1-AI37113) and SEC from the Howard Hughes Medical Institute for a predoctoral fellowship. SEC and TMH contributed to this manuscript by providing the purified expressed protein chemokines.

\footnotetext{
Published online May 22, 2006

Address reprint requests to Dr. J. A. Leary, Genome Center, Department of Chemistry and Molecular Cell Biology, University of California at Davis, One Shields Road, Davis, CA 95616, USA. E-mail: jaleary@ucdavis.edu *Also with the Department of Chemistry, University of California at Berkeley, Berkeley, CA.

tAlso with the Department of Molecular and Cell Biology, University of California at Berkeley, Berkeley, CA.

$\ddagger$ Present address: Genentech, Inc., South San Francisco, CA 94080.
} 